\title{
Bidirectional Grammar and Bidirectional Optimization
}

\author{
Reinhard Blutner \& Anatoli Strigin
}

\begin{abstract}
The human language faculty is a bidirectional system, i.e. it can be used by processes of approximately equal computational complexity to understand and to generate utterances of a language. We assume the general framework of optimality theory and treat the language faculty as a constraint-based system where the very same constraints are used both in comprehension and in generation. In the simplest case comprehension and generation can be modelled by unidirectional optimization: finding an optimal interpretations for a given speech input in the case of comprehension; producing an optimal expression for a given message in case of generation. In the simplest case, the speaker and the listener roles are strictly separated. However, there are linguistic observations which indicate that the listener's and the speaker's perspectives are integrated to some extent. Bidirectional optimization is an explicit proposal for doing the integration.

In this article we propose a general architecture of the language faculty and discuss the precise extent to which speakers are listener-oriented and/or listeners are speaker-oriented. Interestingly, this extent does not seem to vary with regard to the different subsystems considered: the sensorimotor system, the system of grammar proper and the conceptual-intentional system (pragmatics). Though the experimental evidence is not very strong at the moment it seems in online processing the speaker takes the hearer into account but not vice versa. Besides the online (actual processing) view of bidirectionality we discuss bidirectional optimization as an offline phenomenon taking place during language acquisition, and giving rise to fossilization phenomena.
\end{abstract}

\section{Introduction}

In the computational linguistics literature (e.g. Appelt, 1989) a grammar is called bidirectional if it can be used by processes of approximately equal computational complexity to parse and generate sentences of a language. The complexity clause ensures that humans can communicate in a timely manner, i.e. the speaker's speed of generation is just right for comfortably comprehending him. Because computational linguists are concerned with the meanings of sentences that are processed, a bidirectional grammar must specify a correspondence between sentences and meaning representations, and this correspondence must be represented in a manner that allows one to be computed from the other.

Appelt (1989) stresses that to be of use both for production and comprehension, a bidirectional grammar has to be represented declaratively. If any information is represented procedurally, it must necessarily be represented differently for parsing and generation processes, resulting in an asymmetry between the two. Following Appelt, a declarative grammar could be based on the (associative and commutative) unification of feature structures such as the PATR II formalism (Shieber, 1986) or on some more modern forms of constraint-based and inherently nondirectional grammars (for instance see Bresnan, 2000; Jackendoff, 2002). Presently, optimality theory (OT) is the dominant framework for realizing such bidirectional grammars (cf. Prince \& Smolensky, 1993/2004; Smolensky \& Legendre, 2006).

The simplest way to realize comprehension and generation strategies within OT is by unidirectional optimization: speakers try to find the optimal form to express a given meaning; listeners try to find the optimal interpretation for a given form. In the context of computational linguistics the applicability of expressive optimization (speaker's view) has been discussed by Kuhn (2001, 2003). Optimal interpretation (listener's view) has been discussed by Fanselow, Schlesewsky, Cavar, \& Kliegl (1999), Hoeks \& Hendriks (2005), Smolensky \& Legendre (2006), Lamers \& de Hoop (2004), and others, and it as been demonstrated that this view can be used to construct cognitively realistic models of online, incremental interpretation. 
Bidirectional optimization goes beyond the unidirectional optimization account by assuming that the speaker's and the hearer's perspective are integrated into a simultaneous optimization procedure. The motivation for assuming bidirectional optimization comes from the Zipfean idea that the human language faculty is subject to two simultaneous pressures: it must produce well-formed linguistic expressions as efficiently as possible, but it also must produce utterances that can be easily comprehended (Blutner, 1998; Horn, 1984; Zipf, 1949). Often these two pressures are in conflict and bidirectional optimization has to offer a resolution of this conflict. There are two principled ways of how and when the conflict can be resolved: the online processing view suggests that this conflict resolution takes place online during actual utterance interpretation/generation; the fossilization view suggests that the conflict is resolved during several generations of language acquisition. In terms of OT the latter view is expressed as a mechanism of constraint adaptation, i.e. the weighting/ranking of the constraints is changed under the influence of the two diametric Zipfean forces.

To put it in other words, we see two different ways of interpreting bidirectionality in OT. First, there is the assumption of bidirectional optimization as a psychologically realistic online mechanism. According to this online/synchronic view, speakers (hearers) optimize bidirectionally and take into account hearers (speakers) when selecting (interpreting) a natural language expression. This contrasts with the diachronic view of bidirectionality according to which bidirectional optimization takes place during iterated learning and leads to fossilizing the optimal form-interpretation pairs. ${ }^{1}$

In this article we propose a general architecture of the human language faculty which integrates the grammar component, the conceptual-intentional system (usually called pragmatics) and the sensorimotor system. We will consider to what extent the listener's and the speaker's perspectives are integrated in online processing with regard to these three systems. Furthermore, the emerging interplay between fossilization and bidirectional online processing will be discussed in terms of cognitive economy and cognitive resources.

This article is organized as follows. In section 2 we discuss the proposed general architecture of the human language faculty. Three different notions of bidirectionality are introduced in section 3, together with the general idea of fossilization in OT. Section 4 considers empirical evidence for bidirectional optimization in the domain of sensorimotorics. In section 5 the system of bidirectional grammar is considered. Section 6, finally discusses bidirectionality and fossilization in the domain of pragmatics. Section 7 draws some tentative conclusions.

\section{The architecture of the human language faculty}

Intuitively, a grammar is a bidirectional system that relates meanings to forms and forms to meanings. Because the grammar is embedded in the cognitive system, we must not only look at the grammar itself but also at the way it interacts with the other cognitive systems. Figure 1 illustrates the basic design.

\footnotetext{
${ }^{1}$ To make things even more complicated, there is a third possibility to realize conversational implicatures. This third possibility requires real 'mind reading' capacities (conscious reflections) and proceeds offline. Of course, the important question is how to discriminate between such offline implicatures that are not fossilized and their fossilized counterparts. As far we can see none of the existing pragmatic theories has an interesting answer to this long-standing and intriguing question (cf. Cole, 1975). We will ignore the third possibility since we feel the two other options cover what happens under most normal circumstances.
} 


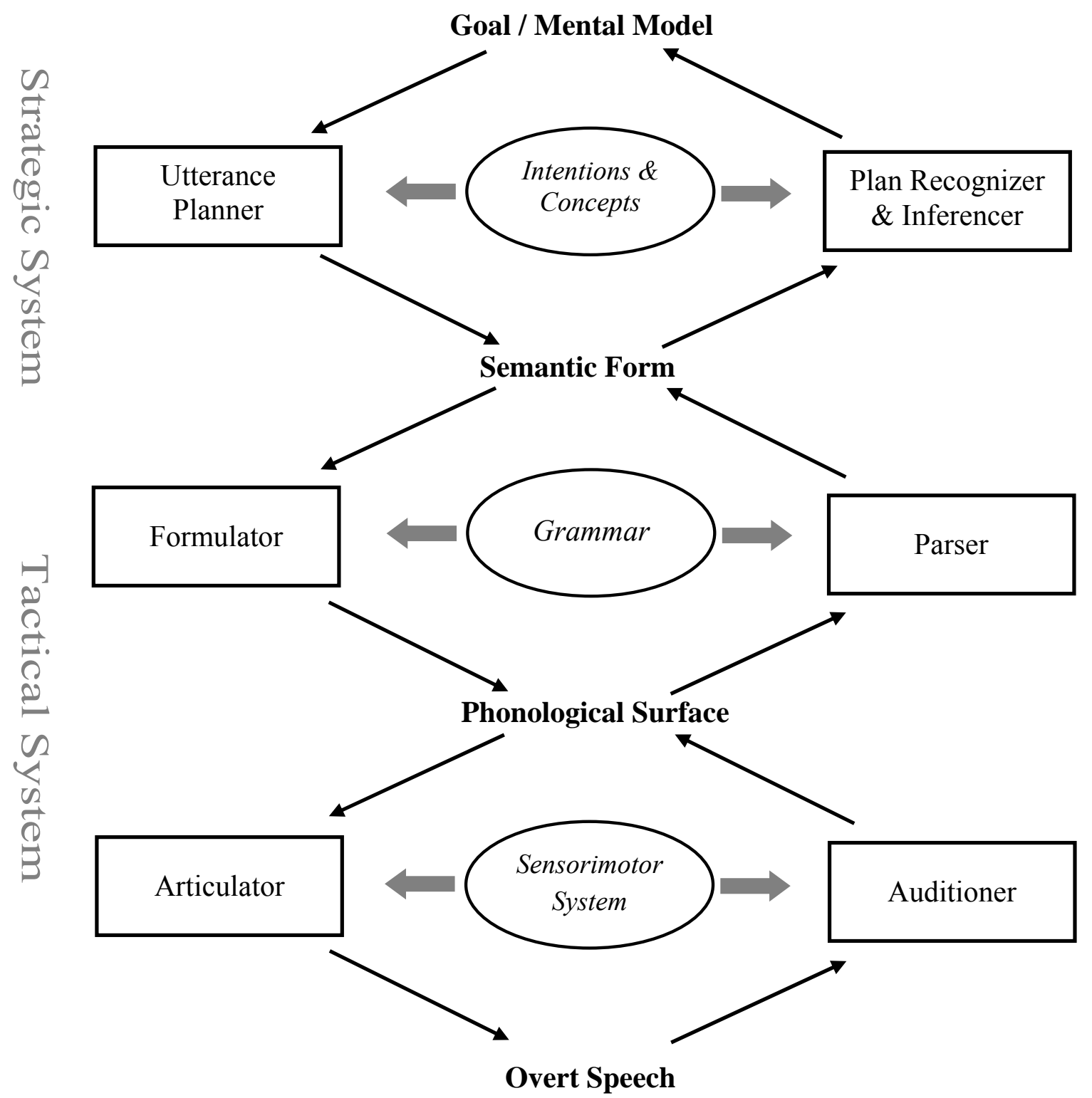

Figure 1: Architecture of the Human Language (freely adapted from Chomsky's minimalist program, cf. Boskovic \& Lasnik, 2006)

As can be seen from figure 1, at least three cognitive subsystems are involved in language production and language interpretation. The conventional basic idea is that (spoken) language is a way to convey thoughts through sounds. Hence, language involves the system of grammar (with its linguistic representations discussed in section 5), the system of thoughts (with its mental representations discussed in section 6) and the system of sound perception and production (with its sensorimotor representations discussed in section 4). We propose that the language model of figure 1 is bidirectional for all three declarative subsystems, i.e. the knowledge schematized in the elliptical forms is used in two directions of processing: comprehension and production.

In the comprehension direction the auditioner maps overt speech (represented as an overt form) to a phonological surface form. The parser maps this form to a semantic representation 
which forms the input for the inferencer and plan recognizer. These mechanisms identify the mental model (Johnson-Laird, 1981) underlying the interpretation of the utterance and the corresponding speech act (Searle, 1969). ${ }^{2}$ In the production direction the utterance planner decides what to say and the formulator/articulator decide how to say it. ${ }^{3}$ More precisely, the formulator maps the semantic representation to the phonological surface and the articulator forms the spoken output from it.

It should be emphasized that the architecture scheme in figure 1 shows merely a relevant subpart of the representations that are involved in language understanding and language production and the links between these representations. The illustration should not be misunderstood as showing the processes that go on in comprehension and interpretation. For example, it would be very naïve to assume that language generation starts with the complete goal/mental model that underlies the intended utterance, and then goes on by developing the consecutive levels in a serial ordering. In a famous essay, Heinrich von Kleist (2002) cites politicians who often start speaking without knowing what they want to say. However, having started to speak often helps them to find out what they want to say (without interrupting their flux of speaking). Von Kleist speaks of "L'idée vient en parlant". ${ }^{4}$ Evidently, any explication of a relevant process should happen behind the scenes rather than in them. Obviously one could illustrate semantic change or sound change using the picture, but the picture itself does not show the process. What we are after are the representations, and the logical links between them, because we consider them to be prior to the processes. ${ }^{5}$

\section{Bidirectional Optimization and Fossilization}

Standardly, OT specifies a relation between two abstract entities, an input and an output. This relation is drawn upon two formal mechanisms, GEN and EVAL. GEN (for Generator) creates possible output candidates on the basis of a given input. EVAL (for Evaluator) uses the particular constraint ranking of the universal set of constraints CON to select the best candidate for a given input from among the candidate set produced by GEN. In phonology and syntax, the input to this process of optimization is an underlying linguistic representation. The output is the (surface) form as it is expressed. Hence, what is normally used in phonology and syntax is unidirectional optimization where the view of the speaker is taken. This contrasts with OT semantics where the view of the hearer is taken as the sole direction of optimization (de Hoop \& de Swart, 2000; Hendriks \& de Hoop, 2001).

The following example gives a simple illustration of how the theory works and what the required devices look like. The example concerns the grammar component with a defined mapping between forms and meanings. Assume we have two forms $f_{1}$ and $f_{2}$ which are semantically equivalent. This means that GEN associates the same interpretations with them, say $m_{1}$ and $m_{2}$. We stipulate that the form $f_{1}$ is less complex (less marked) than the form $f_{2}$ and that the meaning $m_{1}$ is less complex (less marked) than the meaning $m_{2}$. This is expressed by two markedness constraints: $\mathrm{F}$ for forms and $\mathrm{M}$ for meanings $-\mathrm{F}$ prefers $f_{1}$ over $f_{2}$ and $\mathrm{M}$ prefers $m_{1}$ over $m_{2}$. This is indicated by the two leftmost constraints in table 1 .

\footnotetext{
${ }^{2}$ Alternately, we could consider perceptual simulations (Barsalou, 1999) instead of mental models as the basic mental entities underlying conceptual processing.

${ }^{3}$ This is the famous distinction between strategy and tactics which has been adopted in some form in nearly every language generation system built to date (e.g. McKeown, 1985).

${ }^{4}$ This is in fact a parody of the French saying "L'appetit vient en mangeant" which means "One's appetite kicks in once one starts eating."

${ }^{5}$ Thanks to Paul Boersma for clarifying these points to one of the authors in an email conversation.
} 


\begin{tabular}{|c||c|c|c|c|c|c|}
\hline & $\mathrm{F}$ & $\mathrm{M}$ & $\mathrm{F} \rightarrow \mathrm{M}$ & $* \mathrm{~F} \rightarrow * \mathrm{M}$ & $\mathrm{F} \rightarrow * \mathrm{M}$ & $\mathrm{F} * \mathrm{M}$ \\
\hline $\begin{array}{c}r f_{1}, m_{1}> \\
<f_{1}, m_{2}>\end{array}$ & & $*$ & $*$ & & $*$ & \\
$<f_{2}, m_{1}>$ & $*$ & & & $*$ & & \\
$<f_{2}, m_{2}>$ & $*$ & $*$ & & & & \\
\hline
\end{tabular}

Table 1: Markedness and linking constraints in a 2-forms $\times 2$-interpretations design

Besides the markedness constraints, four so-called linking constraints can be formulated. There are precisely four independent linking constraints in the present example. The linking constraint $\mathrm{F} \rightarrow \mathrm{M}$ says that simple (unmarked) forms express simple interpretations. The constraint $* \mathrm{~F} \rightarrow * \mathrm{M}$ says that complex forms express complex interpretations. The two remaining linking constraints express the opposite restrictions. In the present case linking constraints can be seen as lexical stipulations that fix a form-interpretation relation in an instance-based way. ${ }^{6}$

Now let's assume that the two marking constraints outrank all the linking constraints, i.e. $\{\mathrm{F}, \mathrm{M}\}>\left\{\mathrm{F} \rightarrow \mathrm{M}, * \mathrm{~F} \rightarrow * \mathrm{M}, \mathrm{F} \rightarrow{ }^{*} \mathrm{M}, \mathrm{F}^{*} \rightarrow \mathrm{M}\right\}$. Unidirectional optimization then gives the pairings indicated in figure 2a. The pairings realise what Smolensky (1996) considered as the initial state of the learner: every meaning is expressed by the simplest possible expression and every expression is assigned the simplest possible meaning.

The strong version of bidirectional OT (Blutner, 2000) selects all pairs which are optimal from both the listener's and the hearer's perspective. Figure $2 \mathrm{~b}$ shows the corresponding diagram where only one pair comes out as strongly optimal, namely $\left\langle f_{1}, m_{1}\right\rangle$. The potential pairs $\left\langle f_{2}, m_{l}\right\rangle$ is blocked by the cheaper expression variant $\left\langle f_{1}, m_{l}>\right.$, and the potential pair $\left\langle f_{1}\right.$, $m_{2}>$ is blocked by a cheaper meaning variant (again $\left\langle f_{l}, m_{1}>\right.$ ). Hence, strong bidirectionality corresponds to the case of total blocking. Examples are the blocking of *furiosity by fury or *fallacity by fallacy, where all potential meanings are blocked. Furthermore, bidirectional optimization accounts for the phenomena of ineffability (a semantic input does not yield a well-formed syntactic expression as its output) and unintelligibility (a form with no corresponding meaning) in a straightforward way (Beaver \& Lee, 2004; de Hoop, 2001). However, the proposed symmetric version of bidirectionality cannot account for synonymy and ambiguity. If there are any differences in the complexities of the different meanings, then no form can be ambiguous since only one meaning can be selected as the optimal interpretation. Similarly, if there are any differences in the complexities of the different forms, then synonymy cannot exist since each meaning can be expressed by maximally one optimal form.

Figure $2 \mathrm{c}$ shows the pairings under a simple version of asymmetric OT where the listener uses unidirectional optimization but the speaker does it bidirectionally, i.e. he restricts his own optimal productions by checking if he can understand them appropriately. In the given example the model yields synonymy $\left(m_{1}\right.$ is expressed by $f_{1}$ and $\left.f_{2}\right)$ and ineffability $\left(m_{2}\right.$ cannot

\footnotetext{
${ }^{6}$ Mathematically, our linking constraints are equivalent to the bias constraints of Mattausch (2004). To be sure, linking/bias constraints are just meant to be constraints about form-meaning associations, regardless of which forms/meanings are considered as marked. Hence, stating constraints like $* \mathrm{~F} \rightarrow{ }^{*} \mathrm{M}$ instead of $f_{2} \rightarrow m_{2}\left(\right.$ or $*<f_{2}$, $m_{l}>$, or $*\left[f_{2} \rightarrow m_{l}\right]$ ) does not mean to start a test for markedness checking before the linking constraint can be evaluated. The notion of markedness is in the interpretation of the symbols we are using, not in the formal system itself. Hence, it is only for didactical reasons that we prefer the present spelling of the constraints. It simplifies the discussion of structural iconicity and related phenomena.
} 
be expressed). This form of asymmetric OT exhibits Speaker-altruism ${ }^{7}$, i.e. it conforms to a strategy of the speaker that simplifies the task for the listener but makes it more effortful for the speaker. ${ }^{8}$

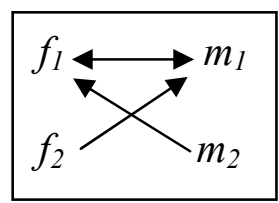

(a)

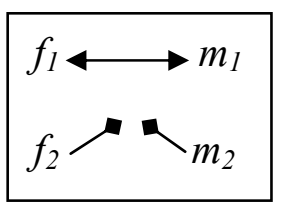

(b)

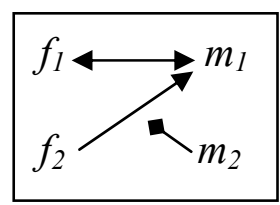

(c)

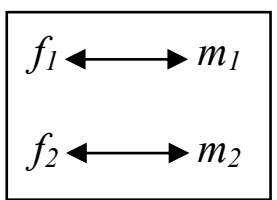

(d)

Figure 2: (a) unidirectional optimization; (b) strong bidirection; (c) asymmetric OT; (d) weak bidirectionality (superoptimality);

Kiparsky (1983) cites examples of partial blocking where a special (less productive) affix occurs in some restricted meaning and the general (more productive) affix picks up the remaining meaning (consider examples like refrigerant - refrigerator, informant - informer, contestant - contester). McCawley (1978) collects a number of further examples demonstrating the phenomenon of partial blocking outside the domain of derivational and inflectional processes. For example, he observes that the distribution of productive causatives (in English, Japanese, German, and other languages) is restricted by the existence of a corresponding lexical causative (the famous kill/cause to die example).

Weak bidirectionality is an iterated version of bidirectionality and provides a solution concept that produces partial blocking instead of total blocking. Figure $2 \mathrm{~d}$ shows the corresponding diagram. Originally, the idea of weak bidirectionality was culled off from the basic principles of neo-Gricean pragmatics (Blutner, 1998) devoted to language change. A form meaning pair is considered superoptimal if it is not blocked by any superoptimal expression/meaning variant of it. Note the recursive character of this definition mentioning the definiens also in the definiendum (cf. Jäger, 2002). It is simple to see that all strongly optimal pairs are also superoptimal. However, there can be superoptimal pairs that aren't strongly optimal, such as the pair $\left\langle f_{2}, m_{2}\right\rangle$ in figure $2 \mathrm{~d}$. In pragmatics, weak OT captures the essence of the pragmatic generalization that "unmarked forms tend to be used for unmarked situations and marked forms for marked situations" (Horn 1984:26).

It is a common observation that there are asymmetries between comprehension and production. For instance, we are often not able to produce what we can nevertheless understand. The opposite situation, where we can produce a certain expression but we cannot understand this expression properly, is also possible though it is observed much less often. Interestingly, the phenomenon of aphasia gives a feasible illustration of the existence of both kinds of asymmetries (e.g. Jakobson, 1941/1968). Likewise, in the domain of language acquisition both sides of the phenomenon can be detected. It is well known that children's ability in production lags dramatically behind their ability in comprehension (e.g. Benedict, 1979; Clark, 1993). It was only recently that attention was also paid to the opposite case

\footnotetext{
${ }^{7}$ It isn't clear if the term Speaker-altruism is really appropriate here. An anonymous referee suggested to call it speaker- egoism since it is the need of the speaker to make sure that the hearer understands him in order to achieve his own (communicative) goals.

${ }^{8}$ In the literature, different forms of asymmetric OT have been proposed. For instance, Hale \& Reiss (1998) and Zeevat (2000) propose an variant where the hearer takes the listener crucially into account (similar to motor theories of perception). For a critical discussion the reader is referred to Beaver \& Lee (2004). The present form of the asymmetric OT was introduced by Boersma (1998, p. 269). It comes close to Wilson's (2001) model; see also Jäger (2004) and Mattausch \& Gülzow (2007) .
} 
where children's comprehension performance lags years behind their ability of production (Hendriks \& Spenader, 2005/2006) .

Unidirectional OT has a very simple answer to the question of how to explain differences between comprehension and production at a certain stage of development. In order to account for the usual observation that comprehension can be perfect while production is not, Smolensky (1996) assumes markedness constraints for forms only, as well as faithfulness constraints - linking forms and meanings (= underlying representations in his system) in an adequate way. He also assumes that the markedness constraints initially dominate the linking constraints. It is exactly under these conditions that we get the expected pattern. This will be demonstrated by going back to our earlier, abstract example with two forms and two meanings.

We assume the markedness constraint $\mathrm{F}$ for forms and the two linking constraints $\mathrm{F} \rightarrow \mathrm{M}$ and $* \mathrm{~F} \rightarrow * \mathrm{M}$ (see table 1). If we further assume the ranking $\{\mathrm{F}\}>>\mathrm{F} \rightarrow \mathrm{M}, * \mathrm{~F} \rightarrow * \mathrm{M}\}$, the result is that the comprehension is always correct, i.e. $f_{l}$ is interpreted as $m_{1}$ and $f_{2}$ is interpreted as $m_{2}$. However, the production perspective sometimes gives the wrong result. This is because of the dominance of the markedness constraint $F$, which gives the result that all meanings $m_{i}(\mathrm{i}=1,2)$ are expressed by the simpler form $f_{l}$. Figure 3 a shows the corresponding pairings in this case of so-called delayed production.

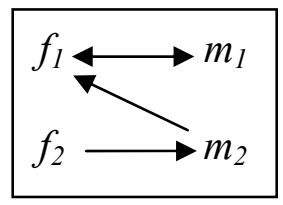

(a)

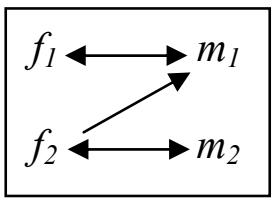

(b)

Figure 3: Asymmetries in unidirectional optimization: (a) a case of delayed production; (b) a case of delayed comprehension

Interestingly, the opposite pattern - called delayed comprehension - is also possible (see figure $3 \mathrm{~b}$ ). In this case we have to assume an incomplete system of linking constraints that outranks the system of markedness constraints. A very simple example is $\{\mathrm{F} \rightarrow \mathrm{M}\}>>\{\mathrm{F}\}$. Now $m_{1}$ produces $f_{l}$ and $m_{2}$ produces $f_{2}$. However, while $f_{l}$ is always interpreted correctly as $m_{1}$ the form $f_{2}$ comes out as ambiguous. It can be interpreted both as $m_{1}$ and $m_{2}$.

The modifier 'delayed' in delayed production/comprehension suggests that there is a mechanism available that can overcome the asymmetry between production and comprehension at some point of the temporal development of the language system. Indeed, there are two such mechanisms that have been discussed recently. The first mechanism is a mechanism of maturation resulting in a processing system that integrates the comprehension and the production perspective (cf. Hendriks \& Spenader, 2005/2006). The result of maturation is a symmetric system of weak bidirectional processing, and the final result corresponds to that given in (2d). Here it is important to understand weak bidirectional processing as online processing. Alternatively, the result of maturation could also be a system of strong bidirection or even an asymmetric system exhibiting Speaker-altruism (taking into account that the initial state has been changed).

The second mechanism is based on OT learning and leads to a reranking of the involved constraints (e.g. Smolensky, 1996). ${ }^{9}$ Basically, the (iterated) learning mechanism leads to the phenomena of conventionalization, fossilization, reanalysis, or reconstruction, and we will

\footnotetext{
${ }^{9}$ Contrasting the mechanism of maturation with the standard OT learning mechanism (reranking of constraints) does not exclude the possibility that as a side effect of maturation some constraints are reranked. In fact, Hendriks' and Spenader's account also needs constraint reranking.
} 
discuss its relevance for the different parts of the language faculty in the following sections. Interestingly, the (recursive) concept of weak bidirectionality can also be interpreted as an offline mechanism coming close to the capacities of the second mechanism. Hence, our present proposal is not to interpret weak bidirectionality as an online mechanism of language processing but as an offline mechanism that has to do with iterated learning and diachronic change.

Which of the two proposed mechanisms is really responsible for overcoming the empirically attested asymmetries between comprehension and production? This is an important research question and we will try to answer it in the following sections.

\section{Bidirectionality and the Sensorimotor System}

Following Boersma (1998) we assume two kinds of phonetic representations: auditory form and articulatory form. The auditory form is a sequence of events relating to the perception of qualities such as pitch, timbre, consonance, and phonetic identity. Contrastingly, the articulatory form is a sequence of gestures of the articulatory apparatus, i.e. a description of the relevant muscle activities affecting the glottis, the larynx, the tongue tip, the tongue body, the velum etc. Following Boersma, we will assume sensorimotor constraints describing our knowledge of what our articulations will sound like and conversely - taking bidirectionality of the corresponding knowledge system into account - describing how to implement articulatorily sounds we aim to produce. Furthermore, a phonological surface form level is assumed to constitute the interface between the system of grammar and the sensorimotor system. As usual, we will take the surface form to be a structure of abstract phonological elements such as phonological features, segments, syllables, and feet. Figure 4 gives a very schematic and simplified picture of the sensorimotor system.

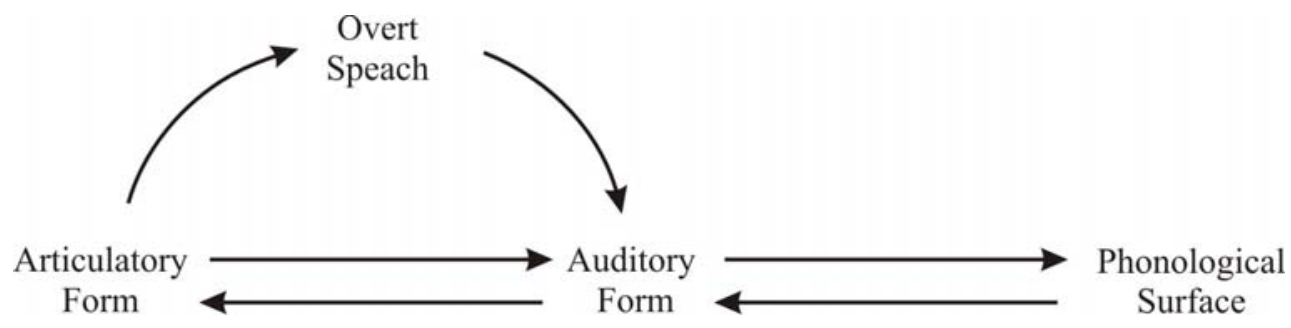

Figure 4: The sensorimotor system: the speaker's perspective maps the phonological surface onto the articulatory form which produces the overt speech; the listener's perspective maps the overt speech onto the auditory form which is interpreted as phonological form.

The articulatory form is restricted by articulatory constraints. The mapping between the phonological surface and the auditory form is restricted by cue constraints (cf. Boersma, this volume).

By using the same system of cue constraints both in perception and in phonetic implementation Boersma \& Hamann (2007) show that the bidirectional use of cue constraints leads to two asymmetries between perception and production, namely the prototype effect and the articulatory effect. The prototype effect describes "the phenomenon that the learner's preferred auditory realization of a certain phonological category is more peripheral than the average auditory realization of this category in her language environment" whereas the 
articulatory effect "limits the auditory form to something that is not too difficult to pronounce". Further, Boersma \& Hamann demonstrate that languages that are evolutionarily stable over generations allow these two conflicting biases to cancel each other out. This results in a balance between distinctivity and articulatory effort. Interestingly, this is derived without the assumption that the learner has any knowledge of auditory distances or goaloriented dispersion mechanism in the whole system.

The work by Boersma \& Hamann (2007) demonstrates the role of bidirectional constraints and bidirectional learning in the sensorimotor system. What about bidirectional online processing in perception/production? For example, we could ask whether the listener takes the speaker into account when perceiving the stream of overt speech. This question pertains to the adequacy of motor theories of speech perception (e.g. Liberman \& Mattingly, 1985). As pointed out by Tatham \& Morton (2006) these theories (and similar analysis-bysynthesis theories) come into trouble when it comes to revealing the kind of invariance needed to uniquely identify phonological objects. Even if extended further, these theories seem to be unable to handle more complex issues such as prosody or expressive content. Furthermore, from the point of view of artificial speech comprehension systems, these theories are extremely cumbersome and time consuming and therefore unsuitable for modelling automatic, incremental natural language perception. Needless to say that also Boersma \& Hamann (2007) reject the analysis-by-synthesis approach (see also Boersma, this volume).

Let's consider now the converse question of whether the speaker takes the listener into account when producing the stream of overt speech. The existence of monitoring devices that evaluate the appropriateness or correctness of ongoing motor activity or response provides convincing evidence for an affirmative answer. In the language domain, for instance, monitoring can manifest itself in the phenomenon of self-repair in speech (Levelt, 1983). Levelt discriminates two kinds of self-repairs: overt and covert. In overt selfrepairs, speech is interrupted and a new attempt is made at producing the correct form (e.g., 'I saw him...I saw her writing a letter). Covert repairs are self-repairs in which errors are intercepted at the level of planning by an inner monitoring mechanism. This inner monitoring mechanism operates via prearticulatory editing. Covert repairs are manifested in various speech disfluencies such as prolongations or pauses. Characteristic is the early onset of these repairs, sometimes just one phoneme has been produced before the repair occurs.

Levelt's (1983) 'perceptual loop theory' localizes monitoring in the perceptual apparatus. Hence, figure 4 can be seen as bidirectional OT reconstruction of this theory. We can identify an inner and an outer loop of speech generation. The inner loop starts with the phonological surface and produces an auditory form and an articulatory representation. The articulatory representation is mapped by the sensorimotor constraints to the auditory form and leads back (perception mechanism) to a phonological surface representation triggering the monitoring process and possibly the repair mechanism. The outer loop takes longer for processing and also includes real articulation of speech. Recently, Hartsuiker and Kolk (2001) have provided computational evidence for Levelt's perceptual loop theory. We will interpret this evidence as suggesting the validity of asymmetric OT in the sensorimotor domain.

We make errors in production, and we also make errors in perception. As for language, we occasionally misread or mishear. To avoid miscommunication, it is important to detect such misperceptions. Does this suggest - similarly to monitoring in production - that we can detect such misperception by taking the production direction into account, i.e. by assuming an analysis by synthesis mechanism? Following Van Herten, Chwilla, \& Kolk (2006), we think that in perception there is just one representation, derived from the input sentence. However, there can be a strong conflict between what is perceived and what is expected to signal the presence of a possible misperception. Hence, it is the context which can trigger reanalysis in 
case of misperceptions. Of course, this idea does not necessarily exclude an analysis-bysynthesis mechanism, but it makes it tremendously superfluous.

What about the idea of fossilization? In the sensorimotor domain this idea corresponds to the reanalysis picture which is quite interesting. As a case in point consider the reanalysis that occurs when in generation a certain effect (say, lengthening of a short - i.e. monomoraic vowel) is "just phonetic", and the next generation step reinterprets this as a phonological effect (say, a long - bimoraic - vowel). ${ }^{10}$

Concluding this section we claim that the existence of certain monitoring devices suggests that a restricted online version of bidirectionality is correct: speakers optimize bidirectionally and take the listener into account whereas there is no evidence that listeners take the speaker into account. Further, examples of reanalysis suggest that the non-supervised learning mechanism can systematically rebuild and restructure the bidirectional constraints of the sensorimotor system. We have to admit, however, that we are not very happy with this solution since we don't know the real cause for this asymmetry. In section 6 we will provide independent evidence showing that the asymmetries found in the pragmatic domain cannot be explained by a fully symmetric processing architecture (unidirectional optimization). Everything should be made as simple as possible, but not simpler.

\section{Bidirectionality and Grammar}

According to Jackendoff (2007) the objective of natural language processing is "to produce a correlated set of phonological, syntactic, and semantic structures that together match sound to meaning" (Jackendoff, 2007: 3). Following standard terminology the bidirectional knowledge system that describes the correlation of sound and meaning is called grammar. Because this correlation is mediated by syntactic structure, the processor must develop a sufficient amount of syntactic structure in both perception and production in order to realize the mapping between sound and meaning. According to Jackendoff's parallel architecture

(i) the grammar is made up of independent generative components for phonology, syntax, and semantics, linked by interfaces (modularity)

(ii) the grammar is constraint-based and inherently nondirectional.

We have to modify these two claims only moderately in order to transform Jackendoff's architecture into the OT picture. First, we accept the idea of modularity in a very weak sense: the generators that produce the different types of inventories and structures are independent generative components. Second, we assume a grammar based on bidirectional constraints. However, we assume that the constraints are violable rather than strict. This naturally leads to the idea of constraint interaction. Like most researchers in OT, we do not assume that the constraints are organized in a modular way, so that there are separate and encapsulated modules for phonological, syntactic, and semantic constraints. Rather, the constraints are assumed to be cross-modular, i.e. they involve a mix of syntactic, semantic, and pragmatic information (Blutner, de Hoop, \& Hendriks, 2005). ${ }^{11}$

In Jackendoff's system special interface rules are introduced to correlate phonological structures with syntactic structures on the one hand and syntactic structures with semantic structures on the other hand. In figure 5 these interfaces are indicated by double arrows with bold lines. According to the cross-modular architecture of the OT system we also have to assume a third kind of correlation that directly connects aspects of the phonological structure

\footnotetext{
${ }^{10}$ Thanks to Paul Boersma for suggesting us this example.

${ }^{11}$ Cross-modular parallelism was introduced to OT phonology and phonetics by Boersma $(2006,2007)$.
} 
with aspects of the semantic structure. ${ }^{12}$ This is indicated by double arrows with dashed lines in figure 5 (in order to signal the deviation from Jackendoff's system).

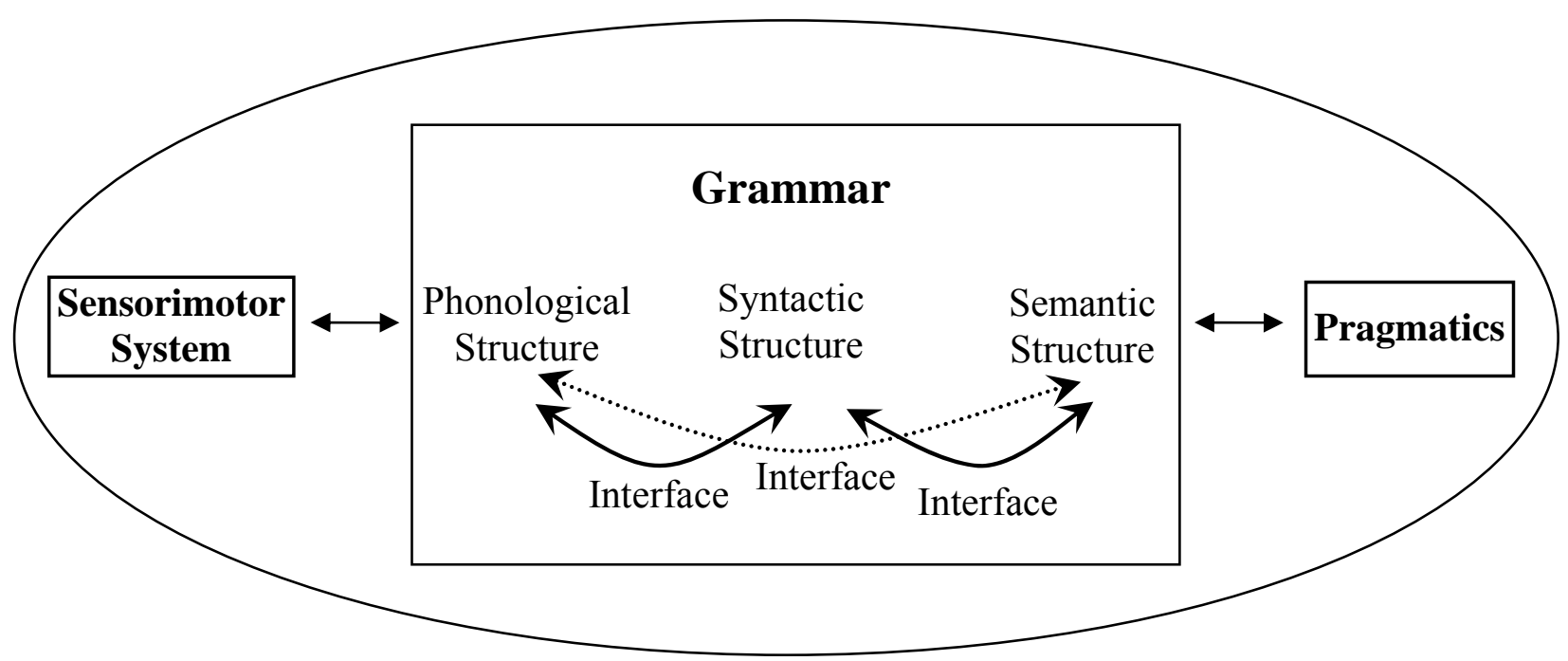

Figure 5: Jackendoff's parallel architecture (adapted from Jackendoff, 2007)

In the present OT variant of Jackendoff's parallel architecture, the interfaces are realized by certain constraint systems that are organized in a cross-modular way, i.e. the rankings of these constraints corresponding to the different interfaces can be completely mixed. Hence, some subset of syntactic constraints can overpower some subset of semantic and phonological constraints whereas another subset of syntactic constraints can be overpowered by a certain subset of semantic or phonological constraints. A similar parallel structure has been proposed by Boersma (2001) where the semantic structures are restricted in the domain of morphemes (see also Apoussidou, 2007; Escudero, 2005; Boersma, this volume).

Quite in agreement with ideas proposed by Goldberg (1995) and Jackendoff (2007) we assume that there is no strict lexicon/grammar distinction: morphemes and words correspond to relatively idiosyncratic constraints in a continuum of generality with more general grammatical constraints. A side effect of this decision is that it opens a simple way to approach grammaticalization and reanalysis phenomena in the area of syntax/semantics. For example, lexical elements can be reanalyzed as grammatical ones. Following Detges \& Waltereit (2002) we will see grammaticalization as a speaker-based phenomenon and reanalysis as a hearer-based procedure. Like any type of change, grammaticalization is ratified by reanalyses on the part of listeners. In this sense we consider reanalysis and grammaticalization as inseparable twins.

The idea of bidirectional constraints and bidirectional learning has been demonstrated in simulation studies by Zeevat \& Jäger (2002) and Jäger (2004). The results of these studies suggest that certain syntactic alignment patterns can be explained completely in a functional way making us of the bidirectional gradual learning algorithm. However, these studies do not allow for a clear prediction about the amount of bidirectionality in online processing. ${ }^{13}$ Before

\footnotetext{
${ }^{12}$ A good example for the direct correlation between phonological structures and semantic structures (focus) is given by Beaver, Clark, Flemming, Jaeger, \& Wolters (2007).

13 Jäger's (2004) bidirectional gradual learning algorithm involves interpretation as well as generation. For the interpretation the standard unidirectional optimization is used whereas bidirectional optimization is used for the generation. Only in cases where no bidirectional solution exists is the unidirectional solution used. Boersma \&
} 
we discuss some relevant experimental work let's shortly discuss this question from the point of view of computational linguistics.

There is an old problem with assuming full symmetric bidirectionality to phonological and syntactic processing in both directions. In phonology, the problem is mostly discussed as the $\mathrm{Rad} / \mathrm{Rat}$ problem. It appears in languages with final devoicing like Dutch or German. The German word Rat (council) is pronounced as [rat] without any change from the underlying form to the surface form. The word / Rad/ (wheel) is pronounced in the same way but here two constraints come into play: the devoicing constraint that prefers the pronunciation [rat] to [rad] and faithfulness that would prefer the pronunciation [rad] and that is outranked by devoicing in German. If we want to apply the same constraints in the direction from pronunciation to optimal underlying form, /Rat/ is always preferred because of faithfulness in interpretation. The same problem can arise with syntactic ambiguities (Zeevat, 2000). Again in German, the sentence (1a) is ambiguous between the two readings given in (1b) and (1c):

(1) a. Welches Mädchen mag Oskar?

b. Which girl likes Oskar?

c. Which girl does Oskar like?

There are different strategies to avoid or to resolve the Rad/Rat problem and its syntactic counterpart. Obviously, the role of context is important in discussing this problem. If we assume that context acts as an external parameter, then we can solve the problem by assuming that in some context, /Rat/-reading is preferred and in another context the / Rad/-reading is preferred. The ambiguity of [rat] is simply explained then by the observation that in some context the optimal interpretation is / Rat/ and in another context it is / Rad/. To get this idea working Boersma (2001) assumes a constraint that directs the fitting of the context and can overpower phonological and syntactic constraints (conforming to the idea of a cross-modular constraint organization). This view draws, obviously, on a particular view of ambiguity. It sees ambiguity as an artifact that shows up when we abstract away from context. Under fixed contextual conditions there is no real ambiguity. Interestingly, this argument is much stronger in connection with syntactic ambiguities like (1) where many (naive and untrained) people get the two interpretations only if we construct two different contexts for them.

The $\mathrm{Rad} / \mathrm{Rat}$ problem was originally raised by Hale \& Reiss (1998). The solution they proposed is close to an analysis-by-synthesis procedure: to comprehend a surface form like [rat] requires the generation of a list of underlying forms that produce the same surface form. In the present case both underlying forms /Rat/ and /Rad/ yield the requested surface form [rat], so both are optimal comprehension candidates, to be disambiguated higher up by syntactic, lexical-semantic, or pragmatic constraints. ${ }^{14}$ Hale \& Reiss note that this solution is consistent with well-established priming effects, citing Jackendoff: "The general picture of lexical access during speech perception, then, is that it initially can discriminate only on phonological grounds. Only somewhat later in processing, after the syntactic and conceptual processors have gotten access to the list of possible candidates, can the ultimate choice of word be determined"' (Jackendoff, 1987: 103)

\footnotetext{
Hamann (2007) comment on this procedure as follows: "However, Jäger's Bidirectional Gradual Learning Algorithm relies on a slightly teleological feature of evaluation in production: every candidate form in a production tableau has to be hearer-optimal, i.e. if taken as the input to a comprehension tableau (with the same rankings) it should be mapped to a meaning identical to the input of the production tableau. This explicitly listener-oriented evaluation procedure thus militates against ambiguous (i.e. poorly 'dispersed') forms in production, and Jäger relies on it for establishing the diachronic emergence of pragmatic case marking (which enhances the semantic contrast between subject and object). It would be interesting to investigate whether our arguably simpler procedure (optimize comprehension only, then just speak) would be able to handle the complex cases that Jäger discusses."

${ }^{14}$ A similar account is taken by Zeevat (2000; this volume)
} 
Hale \& Reiss argue against any appeal to top-down processing to resolve the $\mathrm{Rad} / \mathrm{Rat}$ problem. However, this argumentation is not correct since (i) a strong biasing context can select the appropriate reading immediately without activating the other readings, (ii) in cases where the ambiguous target word is not in the center of attention, even a weak disambiguating context is strong enough to select the appropriate reading without activating the nonappropriate readings (Blutner \& Sommer, 1988). And that is exactly what Boersma's (2001) solution predicts by using cross-modal constraints for contextual selection.

A third solution was proposed by Bouma (2008). Following ideas put forward by Antilla and colleagues (Antilla \& Cho, 1998; Anttila \& Fong, 2000) Bouma assumes underspecified, partial rankings that can be described by putting constraints in so-called strata. Using stratified grammars it is possible to achieve ambiguity in comprehension even if bidirectional optimization is taken into account. Unfortunately, Bouma (2008) does not discuss a learning theory for stratified grammars. This makes an evaluation of this theory difficult since the bidirectional learning account is crucial for many applications of bidirectionality including fossilization phenomena.

Taking the intriguing debate about the $\mathrm{Rad} / \mathrm{Rat}$ problem and related problems into account makes it fairly difficult to draw any clear conclusions concerning the question of the amount of bidirectionality in online processing. In the final part of his section we will discuss this question in the light of recent findings in psycholinguistics. The basic idea of a psychologically realistic theory of OT is the postulate "that the parser's preferences reflect its attempt to maximally satisfy the grammatical principles in the incremental left-to-right analysis of a sentence" (Fanselow et al., 1999). In OT syntax the production perspective is normally taken. It optimizes syntactic structures with respect to a semantic input. In natural language parsing, naturally, the comprehension perspective is adopted. That means the parser optimizes underlying structures with respect to a surface input. Gibson \& Broihier (1998), Fanselow et al. (1999), Hoeks \& Hendriks (2005), Smolensky \& Legendre (2006), Lamers \& de Hoop (2004), and others have shown that parsing preferences can be explained in this way, and they have convincingly demonstrated that the same constraints seem to be used both in OT syntax and in parsing. This is a powerful argument supporting the psychological reality of an OT grammar.

At this moment there is no need to include the Speaker's perspective in order to account for parsing preferences and garden path effects. Moreover, the idea of robustness of comprehension (Smolensky, 1996; Tesar \& Smolensky, 2000) suggests that even ungrammatical sentences can be parsed (using unidirectional, interpretive optimization). ${ }^{15}$ However, for realizing that a given sentence is ungrammatical the other direction (speaker's perspective) becomes relevant. Since grammaticality judgments are not part of the normal comprehension process they are normally classified as offline phenomena. In the previous section we have seen that things are possibly different in production. In the present case the existence of a syntactic repair mechanism (e.g. Friederici, Hahne, \& Saddy, 2002) suggests a similar conclusion: as speakers we automatically understand what we say.

The existence of a syntactic repair mechanism (conforming to the existence of bidirectional processing in production) does not mean that speakers always avoid temporarily ambiguous, difficult to comprehend sentences. Normally, only a few speakers include the that-complementizer in sentences such as (2):

\section{(2) a. The coach knew (that) you missed practice}

\footnotetext{
${ }^{15}$ There is real empirical evidence for this suggestion, at least in phonology/phonetics: speech-like sounds that do not normally occur in a listener's language will be perceived by the listener in terms of the categories of her language. Such things typically occur in foreign language perception and in loanword adaptation. Boersma (2007) has called this "robust perception" (see also Boersma \& Hamann, 2008). Thanks go to Paul Boersma for this hint.
} 
b. The coach knew (that) she missed practice

When sentences with sentence complements are produced in their reduced form - i.e. without the optional function words - they may constitute garden path sentences as example (2a) shows. Hence, the use of that avoids the temporary ambiguity in example (2a). Example (2b) does not exhibit this temporary ambiguity since the pronouns she/her occur in complementary distribution with respect to subject versus object roles. Hence, if speakers tend to avoid temporary ambiguities (modeled by bidirectional, incremental processing) they should produce significantly more optional function words in examples like (2a) than in examples like (2b).

In a recent study by Ferreira \& Dell (2000) a sentence recall paradigm was used to test this hypothesis. Surprisingly, no significant difference was found suggesting that speakers are selfish, exploiting the flexibility of language to ease only the task of creating sentences. However, when the "communicative pressure" was manipulated and increased (Experiment 6 ), this affected optional word mention in the expected direction. Hence, speakers can change their overall level of that-mention when understandability is important. Under this condition bidirectionality seems to be important in incremental sentence production. We see no relevant experiment that analogously demonstrates the need for bidirectionality in incremental natural language parsing.

\section{Pragmatics in OT}

In OT pragmatics, the bidirectional view of optimization is motivated by a reduction of Grice's maxims of conversation to two principles: the R-principle, which can be seen as the force of unification minimizing the Speaker's effort, and the Q-principle, which can be seen as the force of diversification minimizing the Auditor's effort (e.g. Atlas \& Levinson, 1981; Horn, 1984). Hence, OT pragmatics can be considered as a formalization of the neo-Gricean view of pragmatics (Blutner, 2000). In terms of OT pragmatics, the idea behind interpretive optimization is to select the most coherent interpretation. What is meant by coherence has to be expressed by particular OT constraints, such as formulated, for instance, by Zeevat (2007). The principle of interpretive optimization is a very abstract one which has to be supplemented by a system of ranked constraints in order to constitute a system that is able to express something like Horn's R-principle. The simultaneous use of expressive optimization can be seen as similar to the role of Horn's Q-principle - it acts as a blocking mechanism which blocks all the outputs which can be expressed more economically by an alternative linguistic input. Again, what counts as more economical has to be expressed by the system of constraints.

In the previous sections we have stressed two different ways of interpreting bidirectional optimization: (1) as a psychologically realistic online mechanism; (2) as a mechanism taking place offline, e.g. during language acquisition - if repeated it is fossilizing the optimal forminterpretation pairs. Besides unidirectional optimization, we have suggested strong bidirectionality and asymmetric bidirectionality for the former mechanism (cf. section 3, especially figure 2a-c). The solution concept of weak bidirectionality was suggested to capture the fossilization and the diachronic dimension of language (Blutner, 2000, 2007; Blutner \& Zeevat, to appear). Weak bidirectionality captures the essence of the pragmatic generalization that "unmarked forms tend to be used for unmarked situations and marked forms for marked situations" (Horn 1984:26).

There are at least two - or even three - arguments against viewing weak bidirectionality as describing online pragmatic processing. First, a repeated and conscious change of perspective cannot take place online because of the enormous processing resources that are 
required for it. This point is similar to those made for the system of grammar by Kuhn (2003). Second, assuming that natural language interpretation happens on an incremental, left to right basis, conflicts with the non-local, global nature of the proposed algorithms which calculate the super-optimal solutions (cf. Beaver \& Lee, 2004). Third, there are certain examples of anti-iconicity showing that Horn's division of pragmatic labor and the idea of weak bidirectionality formalizing it are not completely correct and should be seen as an approximation only. The approximation seems to be good enough in cases where markedness and frequency are correlated such that the marked structures are the less frequent ones. Both instances of iconicity and anti-iconicity can be explained when an evolutionary setting is assumed (Benz, 2003; Blutner, Borra, Lentz, Uijlings, \& Zevenhuijzen, 2002; Van Rooy, 2004). In this approach the solution concept of weak bidirectionality is considered as a principle describing the results of language change: super-optimal pairs emerge over time in language change. This relates to the view of Horn (1984) who considers the Q and the I principle as diametrically opposed forces in language change, and it conforms to the idea that synchronic structure is significantly informed by diachronic forces. Interestingly, frequency is the decisive factor in these models.

One important instance of anti-iconicity has been found in connection with semantic broadening where the initial meaning is described as that of an ideal shape, figure or state. A good example can be found in Dutch, where besides the preposition om (= Engl. round; German $\mathrm{um}$ ) the expressions rond and rondom are in use. The expression rond is a word borrowed from French. It refers to the ideal shape of a circle. Starting with its appearance it comes in competition with the original (and unmarked) expression om. The result is a division of labour as demonstrated in the following examples (Zwarts, 2003, 2006):

(3) a. Ze zaten rond (?om) de televisie

They sat round the television

b. Een man stak zijn hoofd om (?rond, ?rondom) de deur

A man put his head round the door

c. De auto reed om (?rond, ?rondom) het obstakel heen

The car drove round the obstacle

d. het gebied rondom (?om) het stadje

the area round the little town

According to the principle of iconicity we would expect that the unmarked form (om) is paired with the ideal of the circle shape and the marked form (rond) with the detour interpretation. ${ }^{16}$ However, the opposite is true. There is a simple explanation of this fact: ideal shapes/situations are much less frequent then non-ideal situations; hence, since the probabilities are $\mathrm{P}\left(m_{1}\right)<\mathrm{P}\left(m_{2}\right)$, the evolutionary approach predicts anti-iconicity. Concluding, our third argument is that weak bidirectionality is best modelled by a mechanism of cultural evolution, an offline mechanism, of course.

What is a psychologically realistic picture of online interpretation/production in connection with the pragmatic tasks? We think recent work by Hendriks and colleagues about the use and acquisition of binding principles (Hendriks, Englert, Wubs, \& Hoeks, 2007; Hendriks, Rijn, \& Valkenier, 2007; Hendriks \& Spenader, 2005/2006) allows one to conclude that the variant of an asymmetric OT introduced in section 3 gives the proper answer. The argument rests on a careful investigation of production/comprehension asymmetries that can be found in connection with some data on binding phenomena.

\footnotetext{
${ }^{16}$ The assumption that the ideal path description (circle) is realizing the unmarked interpretation and the detour interpretation is realizing the marked interpretation is justified by independent thoughts about the preference of the logically strongest interpretation (e.g. Dalrymple, Kanazawa, Kim, Mchombo, \& Peters, 1998).
} 
Let's start with a case of delayed production that demonstrates that comprehension can be perfect while production is not. A good example is given by production and understanding of $\mathrm{R}$-expressions and pronouns as illustrated in (4).

(4) Discourse context: A woman is waiting at the corner. Her girl is eating an ice cream cone.

a. She wears a red shirt.

b. The woman wears a red shirt.

The interpretation of the pronoun in (4a) clearly refers to the discourse topic (her girl). If we want to express the alternative meaning as in (4b) we cannot use the pronoun. Interestingly, young children very often produce such subject pronouns when intending to refer to nontopics. Karmiloff-Smith (1985) found this pattern of production in children until the age of 6 .

As we have mentioned in section 3 , the phenomenon of delayed production can be modeled by assuming markedness conventions that initially dominate linking constraints (see figure $3 \mathrm{a}$ ). In the present case, $f_{1}$ stands for the pronoun and $f_{2}$ for an R-expression. Further, $m_{1}$ is the interpretation referring to the topicalized discourse referent while $m_{2}$ refers to the non-topicalized one. The markedness constraint $\mathrm{F}$ can be seen as an economy assumption preferring pronouns to $\mathrm{R}$-expressions, $\mathrm{F} \rightarrow \mathrm{M}$ expresses the preference for pronouns to be interpreted as the topic of the discourse and and $* \mathrm{~F} \rightarrow * \mathrm{M}$ expresses the preference for $\mathrm{R}$ expressions to be not topicalized. Figure 6a shows the preferences between the four possible form-interpretation pairs that result from assuming that markedness is initially higher ranked than linking. Using unidirectional optimization, the diagram describes the OT system of an agent who can properly understand pronouns and R-expressions but who overuse pronouns when intending to refer to non-topics. Figure $6 \mathrm{~b}$ shows the predicted asymmetry between production and interpretation (note that figure $6 \mathrm{~b}$ is instantiating figure $3 \mathrm{a}) .{ }^{17}$

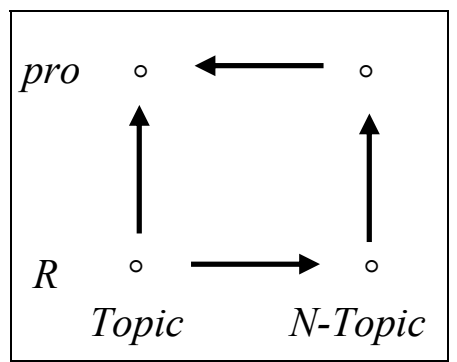

(a)

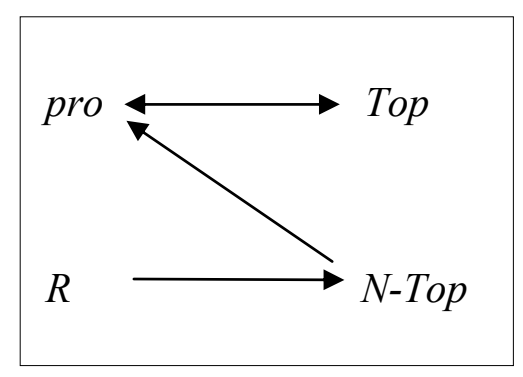

(b)

Figure 6: (a) Preferences between the four form-interpretation pairs based on the system $\{\mathrm{PRO}\}>>$ PRO $\rightarrow \mathrm{TOP}, * \mathrm{PRO} \rightarrow * \mathrm{TOP}\}$ of ranked constraints ${ }^{18}$; (b) Asymmetries in unidirectional optimization calculated from the same system of ranked constraints

In section 3, we introduced two models for describing the transfer from the (asymmetric) child system to the adult system. First, the online processing model overcomes the asymmetry by assuming that the speaker takes the hearer into account and begins to reason bidirectionally at some point of her development. Second, the fossilization view says that unidirectional

\footnotetext{
${ }^{17}$ The constraint $* \mathrm{PRO} \rightarrow * \mathrm{TOP}-$ saying the R-expressions refer to non-topicalized discourse referents - is not really required to derive the pairings shown in figure $6 \mathrm{~b}$ because the content of the R-expression makes the proper choice. Hence, the system $\{\mathrm{PRO}\} \gg\{\mathrm{PRO} \rightarrow \mathrm{TOP}\}$ is sufficient to derive the proper pairings.

${ }^{18}$ For simplicity, we have omitted the constraints PRO->*TOP and *PRO->TOP which are ranked lower than the constraints $\mathrm{PRO} \rightarrow \mathrm{TOP},{ }^{*} \mathrm{PRO} \rightarrow{ }^{*} \mathrm{TOP}$.
} 
optimization is sufficient if it is assumed that there is an (iterated) learning mechanism that reranks the corresponding constraints in a proper way. In the present example the linking constraints are promoted and the markedness constraints are demoted, resulting in the system $\left\{\mathrm{PRO} \rightarrow \mathrm{TOP},{ }^{*} \mathrm{PRO} \rightarrow{ }^{*} \mathrm{TOP}\right\}>>$ PRO $\}$. Figure 7 shows the corresponding diagrams.

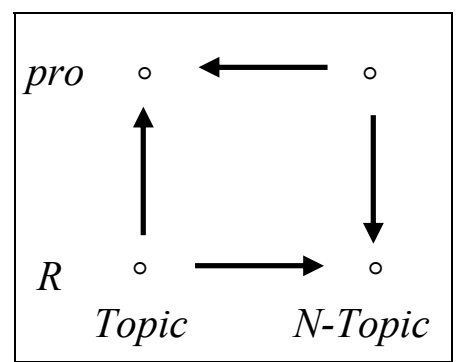

(a)

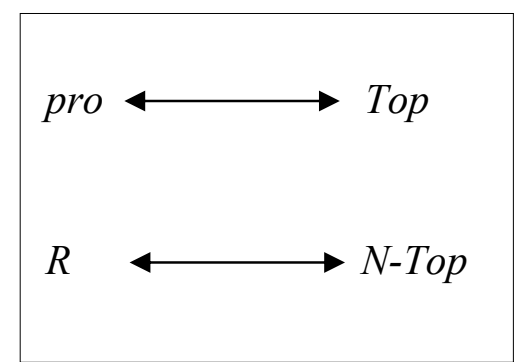

(b)

Figure 7: (a) Preferences between the four form-interpretation pairs based on the system $\{\mathrm{PRO} \rightarrow \mathrm{TOP}, * \mathrm{PRO} \rightarrow * \mathrm{TOP}\}>>$ PRO $\}$ of ranked constraints; (b) Symmetric results of unidirectional optimization.

What empirical evidence can help to discriminate between the two models? In a recent research article, Hendriks, Englert, \& Wubs (2007) argue that the investigation of elderly adults could be decisive. It can be assumed that elderly adults possess the required pragmatic and grammatical knowledge to select and interpret referring expressions. However, their linguistic performance can be defective, due to the decreasing working memory capacity. And indeed, the authors found that elderly adults produce non-recoverable pronouns significantly more often than young adults when referring to the old topic in the presence of a new topic. With respect to the comprehension task, no significant differences were found between elderly and young adults.

Obviously, this experimental outcome is a great problem for the fossilization view, since a stipulation of a mechanism of 'de-fossilization' does not make any sense in the present context. Consequently, the assumption that the speaker takes the hearer into account is well motivated for such examples. Hence, both strong bidirectionality and asymmetric bidirectionality introduced in section 3 are supported by the empirical evidence, and they are good candidate models for further investigation.

Next, let us consider the case of delayed comprehension that was been observed in connection with reflexives. A series of experiments has shown that children make errors in interpreting pronouns as late as age 6;6, yet correctly comprehend reflexives from the age of 3;0 (e.g. Chien \& Wexler, 1990; Koster, 1993; McKee, 1992; Spenader, Smits, \& Hendriks, 2007). For instance, children were confronted with sentences such as (5a) and (5b) and a corresponding picture with an elephant and an alligator was shown. In some trials the elephant was hitting himself on the picture.

(5) Discourse context: Here is an elephant and an alligator.

a. The elephant is hitting himself.

b. The elephant is hitting him.

In the experiment (Spenader et al., 2007) children until at least the age of 7 said that both sentence (5a) and sentence (5b) matched the picture showing an elephant hitting himself. Hence, the pronoun leads to errors in interpretation for the asked children. Contrasting with the comprehension data, language production experiments consistently have shown that 
children do not have problems in producing reflexives or pronouns correctly. For example, Bloom et al. (1994) demonstrated that even in the youngest age groups investigated (ranging from $2 ; 3$ to $3 ; 10$ ) the children consistently used the pronoun to express a disjoint meaning, while they used the reflexive to express a coreferential interpretation. It can be concluded from the production data that children have competence of binding principles. Why don't they use this knowledge in comprehension then?

An answer in terms of OT pragmatics was given by Hendriks \& Spenader (2005/2006). As discussed in section 3 the case of delayed comprehension can be described by an incomplete system of linking constraints that outranks the system of markedness constraints. In the case under discussion Hendriks \& Spenader assumed the markedness constraint called "referential ecomomy" (see Burzio, 1998). It prefers the reflexive over the pronoun. Further, principle A of binding theory was assumed as a violable constraint (excludes the reflexive from the disjoint interpretation), and it was assumed that linking dominates markedness. This leads to a diagram such as (3b) illustrating delayed comprehension.

Hendriks \& Spenader assume the processing view with bidirectional optimization: the hearer takes the speaker into account. Unfortunately, this leads to a problem with the behavior of elderly people, since it predicts that elder people should have problems in understanding pronouns, which obviously is wrong. It can be concluded from this observation that in this case the fossilization mechanism is the proper way of explaining the data.

Taking all things together, we claim that a combination of fossilization and asymmetric bidirectionality fits the available data best. The assumption that the speaker takes the hearer into account but not vice versa explains the data with the referring expression. The same assumption plus the idea of fossilization explain the reflexive pronoun data. As mentioned earlier we would like to see a more symmetric solution for conceptual reasons, but we don't see it at the moment. Alternatively, the present online processing model could be questioned since it stipulates rather than explains the transfer from unidirectional to bidirectional reasoning. Mattausch \& Gülzow (2007) propose a solution that avoids the assumptions of the online processing model. The prize they have to pay is the stipulation of a rather complex concept of asymmetric optimization.

\section{Conclusions}

We have argued for conceptualizing the human language faculty as a bidirectional system, which can be used by processes of approximately equal computational complexity to understand and to generate utterances of a language.

Furthermore, we have discussed two principled ways of how (and when) the conflict between the two diametric Zipfean forces can be resolved. The first view (bidirectional online processing) suggests that this interaction takes place online during actual utterance interpretation/generation. The second view (fossilization) suggests that the conflict is resolved during bidirectional learning. We have argued that neither of these extreme views gives a complete fit to the known empirical data when taken per se. While it is obvious that fossilization phenomena are real to some extent, it can also be argued that an asymmetric online version of bidirectionality is acceptable: speakers optimize bidirectionally and take the hearer into account when enough processing resources are available for calculating the optimal expression. In contrast, hearers do not normally take the speaker into account when the optimal interpretation is calculated. This seems to be true for all the three cognitive subsystems involved in language production and language interpretation: sensorimotorics, grammar, and pragmatics. However, more empirical and theoretical work is needed to decide this difficult issue. 
Future work should be devoted to discuss the emerging interplay between fossilization and (asymmetric) bidirectional processing in terms of cognitive economy and cognitive resources. It appears that in particular cases it is more economical to store the relevant information directly in the long term memory (and to retrieve it when required) than to perform complex calculations for computing it from the given input. In other cases the opposite is true: the storage in long term memory is highly resource-demanding but there is a fast and simple possibility of calculating the information explicitly. The required balancing between fossilization and restricted bidirectional processing is a highly complex, dynamic process which requires an advanced theory of cognitive resources in order to make precise predictions.

\section{Acknowledgement}

The idea to this article came when Paul Boersma and Henk Zeevat proposed a research group that brings together people from bidirectional phonology \& phonetics with people from bidirectional pragmatics. Hence, we first of all have to thank Paul and Henk for this initiative and for their important contributions to the discussion, which is partially reflected in this article. We further acknowledge valuable discussion with Anton Benz, Hartmut Fitz, Helen de Hoop, Petra Hendriks, Jason Mattausch, and two anonymous referees.

\section{References}

Antilla, A., \& Cho, Y.-M. (1998). Variation and change in optimality theory. Lingua, 104, 3156.

Anttila, A., \& Fong, V. (2000). The partitive constraint in optimality theory. Journal of Semantics, 17, 281-314.

Apoussidou, D. (2007). The Learnability of Metrical Phonology: LOT; Universiteit van Amsterdam [Host].

Appelt, D. E. (1989). Bidirectional Grammars and the Design of Natural Language Generation Systems. In Y. Wilks (Ed.), Theoretical Issues in Natural Language Processing 3 (pp. 206-212). Hillsdale, N.J.: Erlbaum.

Atlas, J. D., \& Levinson, S. C. (1981). It-clefts, informativeness and logical form. In P. Cole (Ed.), Radical Pragmatics (pp. 1-61). New York: Academic Press.

Barsalou, L. W. (1999). Perceptual symbol systems. Behavioral and Brain Sciences, 22, 577609.

Beaver, D., Clark, B., Flemming, E., Jaeger, T. F., \& Wolters, M. (2007). When Semantics Meets Phonetics: Acoustical Studies of Second Occurrence Focus. Language, 83.

Beaver, D., \& Lee, H. (2004). Input-output mismatches in OT. In Palgrave/Macmillan (Ed.), Optimality Theory and Pragmatics. Houndmills, Basingstoke, Hampshire.

Benedict, H. (1979). Early Lexical Development: Comprehension and Production. Journal of Child Language, 6, 183-200.

Benz, A. (2003). Partial Blocking, associative learning, and the principle of weak optimality. In J. Spenader \& A. Eriksson \& Ö. Dahl (Eds.), Proceedings of the Stockholm Workshop on Variation within Optimality Theory (pp. 150-159). Stockholm.

Bloom, P., Barss, A., Nicol, J., \& Conway, L. (1994). Children's knowledge of binding and coreference: Evidence from spontaneous speech. Language, 70, 53-71.

Blutner, R. (1998). Lexical pragmatics. Journal of Semantics, 15, 115-162.

Blutner, R. (2000). Some aspects of optimality in natural language interpretation. Journal of Semantics, 17, 189-216. 
Blutner, R. (2007). Optimality Theoretic Pragmatics and the Explicature/Implicature Distinction. In N. Burton-Roberts (Ed.), Pragmatics (pp. 67-89). Houndmills, Basingstoke, Hampshire: Palgrave/MacMillan.

Blutner, R., Borra, E., Lentz, T., Uijlings, A., \& Zevenhuijzen, R. (2002). Signalling games: Hoe evolutie optimale strategieen selecteert, Handelingen van de 24ste NederlandsVlaamse Filosofiedag. Amsterdam: Universiteit van Amsterdam.

Blutner, R., de Hoop, H., \& Hendriks, P. (2005). Optimal Communication. Stanford: CSLI Publications.

Blutner, R., \& Sommer, R. (1988). Sentence Processing and Lexical Access: The Influence of the Focus-Identifying Task. Journal of Memory and Language, 27, 359-367.

Blutner, R., \& Zeevat, H. (to appear). Optimality-Theoretic Pragmatics. In C. Maienborn \& K. v. Heusinger \& P. Portner (Eds.), Semantics: An International Handbook of Natural Language Meaning. Berlin: Mouton de Gruyter.

Boersma, P. (1998). Functional phonology. The Hague: Holland Academic Graphics.

Boersma, P. (2001). Phonology-semantics interaction in OT, and its acquisition. Papers in Experimental and Theoretical Linguistics, 6, 24-35.

Boersma, P. (2006). Prototypicality judgments as inverted perception. In G. Fanselow \& C. Féry \& M. Schlesewsky \& R. Vogel (Eds.), Gradience in Grammar: Generative Perspectives (pp. 167-184). Oxford: Oxford University Press.

Boersma, P. (2007). Some listener-oriented accounts of h-aspiré in French. Lingua, 117, 1989-2054.

Boersma, P., \& Hamann, S. (2007). The evolution of auditory contrast.Unpublished manuscript.

Boersma, P., \& Hamann, S. (2008). Loanword adaptation as first-language phonological perception.Unpublished manuscript.

Boskovic, Z., \& Lasnik, H. (Eds.). (2006). Minimalist Syntax: The Essential Readings. Oxford: Blackwell.

Bouma, G. (2008). Starting a sentence in Dutch: A corpus study of subject-and objectfronting. University of Groningen, Groningen.

Bresnan, J. (2000). Optimal Syntax In J. Dekkers \& F. v. d. Leeuw \& J. v. deWeijer (Eds.), Optimality Theory: Phonology, Syntax, and Acquisition. : Oxford University Press.

Burzio, L. (1998). Anaphora and soft constraints. In P. Barbosa \& D. Fox \& P. Hagstrom \& M. McGinnis \& D. Pesetsky (Eds.), Is the best good enough? Cambridge, Mass.: The MIT Press.

Chien, Y.-C., \& Wexler, K. (1990). Children's knowledge of locality conditions on binding as evidence for the modularity of syntax and pragmatics. Language Acquisition, 13, 225 295.

Clark, E. V. (1993). The Lexicon in Acquisition. Cambridge: Cambridge University Press.

Cole, P. (1975). The synchronic and diachronic status of conversational implicature. In P. Cole \& J. L. Morgan (Eds.), Syntax and Semantics, Volume 3: Speach Acts (pp. 257288). San Diego, Cal.: Academic Press, Inc.

Dalrymple, M., Kanazawa, M., Kim, Y., Mchombo, S., \& Peters, S. (1998). Reciprocal expressions and the concept of reciprocity. Linguistics and Philosophy, 21, 159-210.

de Hoop, H. (2001). Making sense: The problem of unintelligibility, GAGL 44 (Making Sense: from lexeme to discourse) (Vol. 44, pp. 187-194). Groningen: Department of Linguistics, University of Groningen.

de Hoop, H., \& de Swart, H. (2000). Temporal adjunct clauses in optimality theory. Rivista di Linguistica, 12, 107-127.

Detges, U., \& Waltereit, R. (2002). Grammaticalization vs. reanalysis: A semantic-pragmatic account of functional change in grammar Zeitschrift für Sprachwissenschaft, 21, 151195. 
Escudero, P. (2005). The attainment of optimal perception in second-language acquisition. Doctoral thesis, University of Utrecht.

Fanselow, G., Schlesewsky, M., Cavar, D., \& Kliegl, R. (1999). Optimal parsing, syntactic parsing preferences, and Optimality Theory. Available from ROA 367-1299.

Ferreira, V. S., \& Dell, G. S. (2000). Effect of Ambiguity and Lexical Availability on Syntactic andLexical Production. Cognitive Psychology, 40, 296-340.

Friederici, A. D., Hahne, A., \& Saddy, D. (2002). Distinct neurophysiological patterns reflecting aspects of syntactic complexity and syntactic repair. Journal of Psycholinguistic Research 31, 45-63.

Gibson, E., \& Broihier, K. (1998). Optimality theory and human sentence processing. In P. Barbossa \& D. Fox \& P. Hagstrom \& M. McGinnis \& D. Pesetsky (Eds.), Is the Best Good Enough. Optimality and Competition in Syntax (pp. 157-191). Cambridge, Mass.: The MIT Press.

Goldberg, A. E. (1995). Constructions: A Construction Grammar Approach to Argument Structure: University Of Chicago Press.

Hale, M., \& Reiss, C. (1998). Formal and empirical arguments concerning phonological acquisition. Linguistic Inquiry, 29, 656-683.

Hartsuiker, R. J., \& Kolk, H. H. J. (2001). Error Monitoring in Speech Production: A Computational Test of the Perceptual Loop Theory. Cognitive Psychology, 42, 113157

Hendriks, P., \& de Hoop, H. (2001). Optimality theoretic semantics. Linguistics and Philosophy, 24, 1-32.

Hendriks, P., Englert, C., Wubs, E., \& Hoeks, J. (2007). Age differences in adults' use of referring expressions. Unpublished manuscript, University of Groningen.

Hendriks, P., Rijn, H. v., \& Valkenier, B. (2007). Learning to reason about speakers' alternatives in sentence comprehension: A computational account. Lingua, 117, 18791896.

Hendriks, P., \& Spenader, J. (2005/2006). When production precedes comprehension: An optimization approach to the acquisition of pronouns. Language Acquisition, 13, 319348.

Hoeks, J. C. J., \& Hendriks, P. (2005). Optimality Theory and Human Sentence Processing: The Case of Coordination.

Horn, L. (1984). Towards a new taxonomy of pragmatic inference: Q-based and R-based implicature. In D. Schiffrin (Ed.), Meaning, form, and use in context: Linguistic applications (pp. 11-42). Washington: Georgetown University Press.

Jackendoff, R. (1987). Consciousness and the computational mind. Cambridge, Mass.: MIT Press.

Jackendoff, R. (2002). Foundations of Language. Oxford: Oxford Univeristy Press.

Jackendoff, R. (2007). A Parallel Architecture Perspective on Language Processing. Brain Research 1146, 2-22.

Jäger, G. (2002). Some notes on the formal properties of bidirectional optimality theory. Journal of Logic, Language and Information, 11, 427-451.

Jäger, G. (2004). Learning constraint sub-hierarchies. The bidirectional gradual learning Algorithm. In R. Blutner \& H. Zeevat (Eds.), Pragmatics and Optimality Theory. Houndmills, Basingstoke, Hampshire: Palgrave Macmillan.

Jakobson, R. (1941/1968). Child Language, Aphasia and Phonological Universals. The Hague: Mouton.

Johnson-Laird, P. N. (1981). Mental models of meaning. In B. L. W. a. I. S. Aravind K. Joshi (Ed.), Elements of Discourse Understanding (pp. 106-126). Cambridge: Cambridge University Press. 
Karmiloff-Smith, A. (1985). Language and cognitive processes from a developmental perspective. Language and Cognitive Processes, 1, 61-85.

Kiparsky, P. (1983). Word-formation and the lexicon. Paper presented at the Proceedings of the 1982 Mid-America Linguistic Conference, Kansas.

Kleist, H. v. (2002). Die allmähliche Verfertigung der Gedanken beim Reden. Stuttgart Reclam.

Koster, C. (1993). Errors in Anaphora Acquisition. Unpublished Ph.D. Dissertation, Utrecht University, Utrecht.

Kuhn, J. (2001). Formal and computational aspects of optimality-theoretic syntax. Unpublished Ph. D. dissertation, Universität Stuttgart.

Kuhn, J. (2003). Optimality-Theoretic Syntax - A Declarative Approach. Stanford, CA: CSLI Publications.

Lamers, M., \& de Hoop, H. (2004). Animacy information in human sentence processing: An incremental optimization of interpretation approach. H. Christiansen et al. CSLP, 158171.

Levelt, W. J. M. (1983). Monitoring and self-repair in speech. Cognition, 14, 41-104.

Liberman, A., \& Mattingly, I. (1985). The motor theory of speech perception revised. Cognition, 21, 1-36.

Mattausch, J. (2004). Optimality Theoretic Pragmatics and Binding Phenomena. In R. Blutner \& H. Zeevat (Eds.), Optimality Theory and Pragmatics. Houndmills, Basingstoke, Hampshire: Palgrave/Macmillan.

Mattausch, J., \& Gülzow, I. (2007). A note on acquisition in frequency-based accounts of Binding Phenomena. In I. Gülzow \& N. Gagarina (Eds.), Frequency Effects in Language Acquisition: Defining the Limits of Frequency as an Explanatory Concept (pp. 331-357). Berlin. New York: Mouton de Gruyter.

McCawley, J. D. (1978). Conversational implicature and the lexicon. In P. Cole (Ed.), Syntax and Semantics 9: Pragmatics (pp. 245-259). New York: Academic Press.

McKee, C. (1992). A Comparison of Pronouns and Anaphors in Italian and English Acquisition. Language Acquisition, 2.

McKeown, K. (1985). Text Generation. Cambridge, England: Cambridge University Press.

Prince, A., \& Smolensky, P. (1993/2004). Optimality theory: Constraint interaction in generative grammar. Rutgers University and University of Colorado at Boulder: Technical Report RuCCSTR-2, available as ROA 537-0802. Revised version published by Blackwell, 2004.

Searle, J. R. (1969). Speech Acts: An Essay in the Philosophy of Language: Cambridge University Press.

Shieber, S. (1986). An Introduction to Unification-Based Approaches to Grammar. Lecture Note Series Vol. 4: Center For the Study of Language and Information, Stanford University.

Smolensky, P. (1996). On the comprehension/production dilemma in child language. Linguistic Inquiry, 27, 720-731.

Smolensky, P., \& Legendre, G. (2006). The Harmonic Mind: From neural computation to optimality-theoretic grammar. Cambridge, Mass.: MIT Press.

Spenader, J., Smits, E.-J., \& Hendriks, P. (2007). Coherent discourse solves the Pronoun Interpretation Problem.Unpublished manuscript, University of Groningen.

Tatham, M., \& Morton, K. (2006). Speech production and perception. Houndmills: Palgrave Macmillan.

Tesar, B., \& Smolensky, P. (2000). Learnability in optimality theory. Cambridge Mass.: MIT Press. 
Van Herten, M., Chwilla, D. J., \& Kolk, H. H. J. (2006). When heuristics clash with parsing routines: ERP evidence for conflict monitoring in sentence perception. Journal of Cognitive Neuroscience, 18, 1181-1197.

Van Rooy, R. (2004). Signalling games select Horn strategies. Linguistics and Philosophy, 27, 493-527.

Wilson, C. (2001). Bidirectional optimization and the theory of anaphoa. In G. Legendre \& J. Grimshaw \& S. Vikner (Eds.), Optimality Theoretic Syntax. Cambridge, MA: MIT Press.

Zeevat, H. (2000). The asymmetry of optimality theoretic syntax and semantics. Journal of Semantics, 17, 243-262.

Zeevat, H. (2007). Optimal Interpretation as an Alternative to Gricean Pragmatics Unpublished manuscript, Universiteit van Amsterdam.

Zeevat, H., \& Jäger, G. (2002). A statistical reinterpretation of harmonic alignment. Paper presented at the 4the Tblisi Symposium on Logic, Language and Linguistics, Tblisi.

Zipf, G. K. (1949). Human behavior and the principle of least effort. Cambridge: AddisonWesley.

Zwarts, J. (2003). Lexical Competition: 'Round' in English and Dutch. In P. Dekker \& R. van Rooy (Eds.), Proceedings of the Fourteenth Amsterdam Colloquium (pp. 229-234). Amsterdam: ILLC.

Zwarts, J. (2006). Om en rond: Een semantische vergelijking. Nederlandse Taalkunde, 11, 101-123. 